\title{
UMA ANÁLISE DA ESCRITA CARCERÁRIA BRASILEIRA CONTEMPORÂNEA
}

\section{Maria Rita Sigaud Soares Palmeira ${ }^{1}$}

Resumo: A partir de 2000, livros escritos por homens presos ou recém-saídos das prisões brasileiras ganharam as páginas dos suplementos culturais de jornais e revistas de grande circulação no país, fosse porque publicados por casas editoriais de algum prestígio, fosse porque parecia haver, naquele momento, maior curiosidade em torno da vida na prisão. A escrita a partir do cárcere se funda em ambivalências que parecem remeter ao modo de sociabilidade das prisões brasileiras. Quando narram a partir da prisão, os autores encarcerados constroem uma perspectiva que, ao mesmo tempo que dialoga com a dos demais presos, confirmando seu pertencimento a esse grupo, procura escapar à condição limitadora do cárcere. A partir da análise dessa produção - em especial, dos livros Memórias de um sobrevivente, de Luiz Alberto Mendes; Diário de um detento, de Jocenir; Vidas do Carandiru, de Humberto Rodrigues; e Sobrevivente André du Rap (do Massacre do Carandiru), de André du Rap e Bruno Zeni -, este texto visa ao estabelecimento das especificidades dessa escrita e dos elementos formais e temáticos que a caracterizam.

Palavras-chave: narrativas do cárcere; prisões brasileiras; literatura brasileira contemporânea.

Abstract: Since the year 2000, books written by prisoners or men who were recently released from Brazilian prisons gained special attention in the cultural supplements of important newspapers and magazines in the country. This may be due to the prestigious publishing houses that released those books, or to the increased curiosity, at that moment, about life in prison. Writing in prison underlies ambivalences that seem to refer to the sociability of Brazilian prisons. When they narrate from the jail, incarcerated authors construct a perspective that is both in tune with that of the other prisoners - thus confirming their belonging to this group - and aiming to escape the limiting condition of prison. Examining this production - in particular, the books Memórias de um sobrevivente [Memories of a Survivor], by Luiz Alberto Mendes; Diário de um detento [Diary of a prisoner], by Jocenir; Vidas do Carandiru [Carandiru Lives], by Humberto Rodrigues; and Sobrevivente André du Rap (do Massacre do Carandiru) [Survivor André du Rap (from the Carandiru Massacre)], by André du Rap and Bruno Zeni -, this text will establish the specificities of this writing and the formal and thematic elements that characterize it.

Keywords: Brazilian prisons; contemporary brazilian literature

1 Doutora em literatura brasileira pela USP. e-mail: rita.palmeira@gmail.com. 


\section{INTRODUÇÃO}

Os autores da escrita prisional contemporânea brasileira parecem destinar sua prosa a dois interlocutores distintos: os pares na prisão e os leitores do mundo externo à cadeia. Esse destinatário ambíguo aparece na escolha do léxico, na estruturação da frase, na recorrência de expressões retificadoras, parênteses, notas de rodapé; na dedicatória, nas fotografias, na reprodução de documentos (sentenças, prontuários etc.), nos agradecimentos, no espaço para a escrita dos companheiros; na necessidade de denúncia dos maus-tratos sofridos na prisão, nas considerações sobre a justiça, nas descrições do espaço, costumes, valores e condutas da prisão. Essas questões aparecem em todos os quatro volumes aqui analisados, lançados no início do século XXI. Se nesse momento o fato de esses homens escreverem sobre a própria situação era algo relativamente inédito nas letras nacionais, chamava ainda mais atenção o modo como o faziam.

A minha aposta é de que a produção literária surgida da prisão estrutura-se em função do confinamento a que eram submetidos seus autores, o qual engendra uma sociedade fechada em si (ainda que reportada ao mundo exterior). Esses novos escritores recuperavam, assim, na hibridez que sucintamente acabo de descrever, os modos de sociabilidade do cárcere. Nesse sentido, não se pode ignorar que a prosa produzida na cadeia é feita a partir dos constrangimentos sofridos por quem está em reclusão, participando, forçadamente, de um ambiente fechado, de obrigatória proximidade física com outros homens. Nesse ambiente, é preciso rapidamente reconhecer as regras a fim de garantir a própria sobrevivência. Há uma necessidade de assimilação dos códigos e valores particulares ao mesmo tempo norteadores e definidores da convivência forçada. A prisão teria um modus operandi pautado por um etos próprio e característico da sobrevivência.

\section{O OLHAR DUPLO}

As interligações que produzem "códigos e comportamentos originais" estão na base das relações prisionais, de uma "sociedade" fechada em si, mas que, para existir, precisa reportar-se ao mundo exterior. Para pensar na célebre formulação de Norbert Elias (2001), se na corte a existência dos não-cortesãos servia, pela diferença, para confirmar a distinção dos cortesãos, na cadeia o mundo exterior é que é visto como sinal de privilégio. Se a escrita produzida a partir da prisão retoma os modos de sociabilidade do cárcere, é preciso entender como esse "modo específico de dependências recíprocas" se configura na escrita produzida a partir de um ambiente coercivo. Na prisão, a rede de relações se dá entre os próprios presos - respeitadas hierarquias várias -, entre os presos e os funcionários (os guardas dos presídios, os carcereiros, os policiais, os funcionários de fóruns etc.), entre os presos e seus familiares/ visitantes. Nessas narrativas, encontram-se situações que tratam na maior parte do tempo da relação entre os próprios presos (quando se debruçam sobre a vida na prisão), mas também tratam da relação que os detentos entretêm com os funcionários, notadamente aqueles que não fazem parte do funcionamento da cadeia ou do presídio, mas os guardas responsáveis pelo transporte até os fóruns, a tropa de choque, ou o estafe de algum modo ligado ao sistema judiciário: os psicólogos (responsáveis por pareceres que podem amainar a pena), advogados, juízes etc. As narrativas são especialmente queixosas com aqueles fun- 
cionários que não estão no ambiente da cadeia, mas que, de alguma forma, contribuem para que a permanência de seus autores lá se dê em condições custosas emocional e fisicamente.

Uma prosa que surge do confinamento em grupo impõe-se como uma escrita que não pode escapar à dimensão coletiva do que se narra, mas que pleiteia a especificidade em um ambiente sem possibilidade para isso. Arma-se daí uma prosa que reivindica em sua forma a tensão que a constitui.

A sociabilidade do cárcere supõe um entrelaçamento das condutas, entendidas como o conjunto de regras imposto pelos e aos detentos, e dos valores, concebidos como a junção de traços compartilhados. Às vezes, condutas e valores têm limiar de difícil determinação. Podem se sobrepor, como quando são narradas cenas cujo desfecho, porque envolveria a revelação de detalhes da dinâmica prisional, é omitido: trata-se da explicitação de uma regra (há coisas sobre as quais é preciso silenciar, porque são próprias da cadeia) e de um valor (não se devem dizer aos de fora as coisas próprias ao cárcere). Trata-se, portanto, de condutas e valores próprios ao universo prisional, mas que, para existir, dependem da expectativa de "estar-fora" daquele ambiente. Os textos reportam-se a todo tempo ao "mundo alémgrades", revelando a ambivalência própria à condição de encarcerado e, no que me interessa mais propriamente, à escrita produzida a partir do cárcere. Os laços que constroem na prisão e que formarão os valores partilhados são, segundo Erving Goffman (1988), próprios às instituições totais, onde os “internados" desenvolvem um processo de confraternização que funcionará como modo de apoiarem-se mutuamente e resistirem a um sistema que os forçou à intimidade.

O modo de sociabilidade precisa ser entendido, portanto, como um sistema que, mediado em texto, supõe um olhar duplo, que se volta ora para dentro da prisão, ora para fora dela, mas muitas vezes para os dois lugares a um só tempo (como em Memórias de um sobrevivente). Esse olhar duplo se constrói em diversas camadas. A primeira delas é a própria situação da escrita: é preciso manter-se leal à conduta prisional (daí o caráter silencioso da narrativa em muitos momentos), mas não a ponto de tê-la como regra única - afinal, a sua possibilidade de reinserção depende do reconhecimento, por parte de quem escreve a partir da prisão, da existência de uma normatividade além-muros prisionais. A segunda camada pode ser vista quando os narradores relatam situações em que seguiram à risca o "regrário" do cárcere, mas o fazem de modo a sinalizar que reconhecem a burla aos preceitos do mundo exterior e, com isso, reivindicam o pertencimento a ele. $\mathrm{Na}$ escolha das estruturas sintáticas (mais ou menos orais), do léxico (mais ou menos formal) e na necessidade de traduzir certos termos ou expressões, percebe-se um terceiro nível, mais propriamente ligado à forma, em que esses autores, a partir da introjeção do que seja uma boa escrita, revelam seu pertencimento e não pertencimento ao que, afinal, é uma condição circunstancial - a de encarcerado. Finalmente, no tocante à materialidade do livro, vê-se, na maior parte dos volumes analisados, a inclusão de seções que criam uma espécie de padrão: agradecimentos, caderno de fotografias, reprodução de documentos. Aqui, parece estar em jogo a credibilidade da narrativa. Como se seus próprios autores partissem do pressuposto de que não seriam críveis, numa mobilização do estigma a que estão expostos muitos daqueles cuja narrativa é de teor testemunhal. 
No caso dos escritores saídos dos presídios paulistas, em sua maioria provenientes das camadas mais pobres da população, sua palavra é duplamente desacreditada, pela origem e pelo delito cometido. A necessidade de valer-se de recursos que lhes permitam ser lidos pelos "não-iguais" disputa espaço com o compartilhamento do livro com o "grupo-de-iguais" (outros detentos). Observe-se um trecho de Memórias de um sobrevivente, de Luiz Alberto Mendes: "Ali [na prisão] tudo era pagar. A semântica do verbo pagar era bastante interessante por ali. Tudo o que nos era fornecido pela cadeia trazia uma ideia de pagamento. A comida não era distribuída, era paga. 'Pagar um sapo' era fazer uma ameaça” (2001, p. 414).

O comentário de Luiz Alberto Mendes é sobre a particularidade do uso de um determinado verbo dentro da cadeia. Ao fazê-lo, alterna registros facilmente identificáveis: um mais coloquial e impreciso ("ali tudo era pagar"); outro mais culto, em que remete a um termo de caráter técnico, ou científico, ou ainda linguístico ("semântica"). Em seguida, recorre a uma construção mais complexa como a voz passiva analítica ("tudo o que nos era fornecido pela cadeia"). O olhar do narrador, ao mesmo tempo que revela sua proximidade com o mundo prisional (conhece suas gírias e o momento exato de empregá-las, a ponto de dissertar a respeito), distancia-se dele porque é capaz de assumir uma ótica que estranha o uso do verbo "pagar", o que não ocorreria se estivesse inteiramente absorvido pelo polo prisional. Nesse sentido, assume-se como um interno, mas, como ao fazê-lo não deixa de estar referido aos padrões sintáticos e lexicais legitimados pelo mundo exterior, revela o caráter contingente de sua condição de encarcerado. A sua presença numa instituição total (e, como sugere Goffman, a própria existência da instituição total) só se dá como tal porque há a perspectiva de sair de lá. ${ }^{2}$

$\mathrm{Na}$ construção sintática, lexical e estilística das frases de Mendes, é possível notar a criação de uma "imagem de si”, mesmo quando não escreve explicitamente sobre si. Quando a constroem, esses escritores revelam, por um lado, ter em conta uma expectativa de leitor que não os outros presos, uma vez que mobilizam, ao que parece, um conjunto de percepções referidas ao mundo exterior. São indícios de determinada apreensão do livro como objeto. Aquilo que mobilizam, em função da incorporação do que seja o leitor externo à cadeia, pode contribuir para que o que ali se conta seja aceito como crível. Assim como as práticas sociais se moldam, a escrita também o fará. Os autores de que trato articulam a imagem que têm de seus leitores e a imagem que seus leitores fazem de alguém que escreve a partir da prisão - ajustando-as a fim de produzir uma escrita que seja confiável e faça sentido a quem é de fora. Ao mesmo tempo, existe a necessidade de não desfazer a imagem que sustentam entre os companheiros de prisão.

Quando fazem questão de nomeá-los ou colocar seus retratos, quando calam a respeito de determinadas práticas, quando criticam o sistema penitenciário e as más condições de cumprimento da pena, quando sustentam que para escrever sobre a cadeia é preciso ter estado lá, os autores dotam sua escrita de uma dimensão ética. Afinal, apostam que ela transforme a percepção a respeito daquele que a produz e do ambiente de onde provém.

2 A literatura feita a partir do cárcere inscreve na sua construção a dinâmica relacional própria a uma instituição coercitiva ou, para retomar Foucault (1984), "onidisciplinar". 


\section{A PROJEÇÃO DO ESTIGMA}

Um texto de teor autobiográfico como os aqui analisados precisa construir uma elaboração da própria existência e trajetória em que é necessário determinar quais os eventos importantes, quais os comentários a incluir - disso resultando uma imagem a respeito de quem narra e é personagem daquela história. Constrangidas pela experiência prisional, de que precisam dar conta, que precisam narrar, essas histórias convergem em traço determinante, o do estigma - ou de uma escrita estigmatizada. Em Sobrevivente André Du Rap, está lá: “Antes de eu ser preso, eu era o André. Eu era o André que estudava, que trabalhava, eu tinha a minha família. À parte as intrigas de família, eu tinha uma família. A partir do momento em que eu fui preso, eu me tornei quem? Não o André, mas o bandido" (2002, p. 106).

No caso de André, o que se vê é a elaboração da situação de estigmatizado, é a reflexão sobre o próprio estigma.

Em Vidas do Carandiru, de Humberto Rodrigues: "Muitos leitores poderão estar se perguntando: 'O que este ex-presidiário pretende, abordando temas de política socioeconômica de nosso país?'. É certo. Fui preso, condenado (sem ser ouvido!) e posteriormente absolvido. Muita gente não conseguiria passar por esse crivo. Lembro os nomes de alguns. Eu passei pelo crivo e, com a dor, a vergonha e o sofrimento, ganhei muito mais maturidade e consciência do sofrimento de nosso povo" (2002, p. 265)

Rodrigues transforma o estigma ("este ex-presidiário") quando faz da sua superação uma prova de suas qualidades. É como se sugerisse que a passagem por uma situação inédita para alguém de sua classe e condição (ele era um publicitário de classe média) o tornasse muito mais sensível para as questões sociais sobre as quais falava àquela altura do livro. Indo um pouco além, vê-se que, nas formulações de André e Rodrigues, estão implícitas ou explícitas as marcas de interlocução. Na pergunta de André (“eu me tornei quem?”) e de Rodrigues ("O que este ex-presidiário pretende, abordando temas de política socioeconômica de nosso país?”) parece haver uma pressuposição de que o leitor os lê como presidiários: pessoas que delinquiram, sem direitos, definitivamente marcadas.

A incorporação do estigma é resultado das coerções, do confinamento, das más condições para cumprimento da pena. Ao elaborarem a condição estigmatizada, incorporando a projeção do que os leitores provavelmente pensariam a respeito daquele comentário, pretensão, expectativa, mostram reconhecer a existência da norma, a existência daquilo que não é visto como fonte de estigma - e mais uma vez elegem como parâmetro o mundo exterior. 


\section{REFERÊNCIAS}

ANDRÉ DU RAP. Sobrevivente André du Rap (do Massacre do Carandiru). (coord. editorial Bruno Zeni). São Paulo: Labortexto Editorial, 2002.

CHARTIER, Roger. Formação social e habitus: uma leitura de Norbert Elias; Textos, impressos, leituras. In: A história cultural: entre práticas e representações. Lisboa: Difel, 1990, pp. 91-119; 121-139.

ELIAS, Norbert. A individualização no processo social. In: A sociedade dos indivíduos. Rio de Janeiro: Jorge Zahar Editor, 1994, pp. 102-125.

A sociedade de corte: investigação sobre a sociologia da realeza e da aristocracia de corte. Rio de Janeiro: Jorge Zahar Editor, 2001.

FOUCAULT, Michel. Sobre a prisão. In: Microfísica do poder. Rio de Janeiro: Edições Graal, 1993 (1a ed. 1979), pp. 129-143.

_. Vigiar e punir: nascimento da prisão. Petrópolis: Vozes, 1984.

Teorias e instituições penais; A sociedade punitiva. In: Resumo dos cursos do Collège de France 1970-1982. Rio de Janeiro: Jorge Zahar Editor, 1997, pp. 17-44.

GOFFMAN, Erving. Estigma: notas sobre a manipulação da identidade deteriorada. Rio de Janeiro: Guanabara Koogan, 1988.

. Manicômios, prisões e conventos. São Paulo: Perspectiva, 1974.

JOCENIR. Diário de um detento: o livro. São Paulo: Labortexto Editorial, 2001.

MENDES, Luiz Alberto. Memórias de um sobrevivente. São Paulo: Companhia das Letras, 2001.

RODRIGUES, Humberto. Vidas do Carandiru: histórias reais. São Paulo: 